\title{
A Era da Multirresistência: Incidência em Dez Anos Numa Unidade de Cuidados Intensivos Neonatais
}

\author{
The Age of Multidrug Resistance: Ten Year Incidence in a \\ Neonatal Intensive Care Unit
}

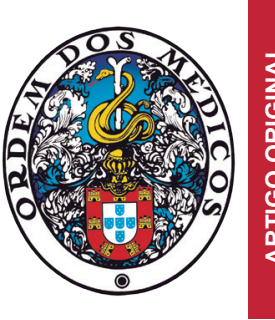

\author{
Bruno SANCHES $\bowtie 1$, Rita GUERREIRO ${ }^{1}$, José DIOGO², Margarida CABRAL ${ }^{1}$, António GOMES ${ }^{1}$ \\ Acta Med Port 2020 Mar;33(3):183-190 - https://doi.org/10.20344/amp.12504
}

RESUMO

Introdução: A emergência de bactérias multirresistentes constitui um desafio médico na atualidade. O objetivo do presente estudo foi determinar a incidência das infeções por bactérias multirresistentes numa unidade de Cuidados Intensivos Neonatais.

Material e Métodos: Estudo de incidência, retrospetivo, descritivo dos episódios infeciosos por bactérias multirresistentes, de 2008 a 2017, numa unidade de apoio perinatal diferenciado.

Resultados: Incluíram-se 64 episódios infeciosos (medianas - idade gestacional: 28 semanas; peso ao nascimento: $885 \mathrm{~g}$ ). As bactérias isoladas foram: Enterobacteriaceae $(n=46)$; Staphylococcus aureus meticilino-resistente $(n=12)$; Acinetobacter baumannii $(n$ = 4); Pseudomonas aeruginosa ( $n=2)$. Identificou-se um fator de risco em $90,6 \%$ dos episódios, destacando-se cateter central $(89 \%)$ e antibioticoterapia prévia (78\%). A taxa de letalidade associada foi 10,9\% (taxa de mortalidade unidade: 4,4\%). A incidência global foi 3,2 episódios infeciosos/100 internamentos, correspondentes a 1,7 episódios/1000 dias de internamento. Verificaram-se três surtos infeciosos com impacto crescente de Enterobacteriaceae.

Discussão: A taxa de incidência descrita reflete uma população de risco, internada numa unidade de Cuidados Intensivos e num período longo de tempo. A distribuição das bactérias isoladas evidencia a evolução da multirresistência relatada internacionalmente, com predomínio crescente de Enterobacteriaceae. A ocorrência de surtos aponta para a necessidade de perceber fatores de risco e meios de disseminação local. A relevância destas infeções está patente na taxa letalidade, superior às infeções hospitalares em geral. Conclusão: A taxa de incidência reflete a dimensão local do problema, constituindo um indicador de qualidade, relevante para o controlo destas infeções.

Palavras-chave: Cuidados Intensivos Neonatais; Farmacorresistência Bacteriana Múltipla; Portugal; Recém-Nascido

\section{ABSTRACT}

Introduction: The emergence of multidrug-resistant bacteria is a medical challenge nowadays. The objective of the present study was to determine the incidence of multidrug-resistant bacteria infections in a neonatal Intensive Care unit.

Material and Methods: Retrospective, descriptive, incidence study of infectious episodes by multidrug-resistant bacteria from 2008 to 2017 in a differentiated perinatal support unit.

Results: Sixty-four infectious episodes included (median gestational age of 28 weeks and birth weight of $885 \mathrm{~g})$. The isolated bacteria were: Enterobacteriaceae $(n=46)$; Methicillin-resistant Staphylococcus aureus $(n=12)$; Acinetobacter baumannii $(n=4)$; Pseudomonas aeruginosa $(n=2)$. A risk factor was identified in $90.6 \%$ of the episodes, with emphasis on central catheter $(89 \%)$ and previous antibiotic therapy $(78 \%)$. The lethality rate of these infections was $10.9 \%$ (Unit mortality rate: $4.4 \%$ ). The overall incidence rate was 3.2 infectious episodes/100 hospitalizations, corresponding to 1.7 episodes/1000 days of hospitalization. There were three infectious outbreaks, with an increasing impact of Enterobacteriaceae.

Discussion: The reported incidence rate reflects a risk population, hospitalized in an Intensive Care unit, over a long period of time. The distribution of isolated bacteria, with Enterobacteriaceae predominance, is in accordance with the shift in multidrug resistance reported worldwide. The outbreaks point to the need of understanding risk factors and means of local dissemination. The relevance of these infections is evident in their lethality rate, which is higher compared to that of general hospital infections.

Conclusion: The incidence rate reflects the local dimension of the problem, representing a quality indicator which is relevant for controlling these infections.

Keywords: Drug Resistance, Multiple, Bacterial; Infant, Newborn; Intensive Care Units, Neonatal; Portugal

\section{INTRODUÇÃO \\ Problema}

Após décadas de mortalidade por infeções comuns, ocorridas na era pré-antibiótica, chegámos a uma nova etapa na história da humanidade - a era da multirresistência. É o resultado da conquista dos seres com maior longevidade biológica, as bactérias, que subsistiram de acordo com as leis de Darwin. $O$ fenómeno evolutivo conduziu à aquisição de mecanismos de resistência bacteriana à terapêutica antimicrobiana, (sobre)utilizada durante várias décadas. Emergiram assim as bactérias multirresistentes (BMR) que constituem uma realidade cada vez mais preocupante, condicionando um acréscimo considerável de morbilidade e mortalidade. Mundialmente estimam-se cerca de 700000 mortes por ano relacionadas com as infeções multirresistentes. ${ }^{1,2} \mathrm{Na}$ Europa, os últimos dados publicados, relativos ao ano de 2015, reportavam cerca de 33000 mortes, com maior impacto nos grupos etários com menos de um e mais de 65 anos de idade. ${ }^{3}$ Portugal configurava-se, nesse estudo, como o quarto país da União Europeia e do Espaço Económico Europeu com maior impacto destas infeções.

\footnotetext{
1. Unidade de Cuidados Intensivos Neonatais. Serviço de Pediatria. Hospital Garcia de Orta. Almada. Portugal.

2. Laboratório de Microbiologia. Serviço de Patologia Clínica. Hospital Garcia de Orta. Almada. Portugal.

$\square$ Autor correspondente: Bruno Sanches. brsan82@gmail.com

Recebido: 02 de julho de 2019 - Aceite: 10 de setembro de 2019 | Copyright @ Ordem dos Médicos 2020
} 
O problema adquire ainda outra dimensão dada a perspetiva de aumento do número de infeções nos próximos anos. ${ }^{1}$ Este incremento está relacionado com três fatores principais. O primeiro relaciona-se com a maior sobrevida de determinados grupos de doentes (idosos, cirúrgicos, transplantados, oncológicos, prematuros extremos) que leva à sobrevida de indivíduos 'imunocomprometidos' e em risco para a colonização/infeção por BMR. ${ }^{4,5}$ Outro fator relaciona-se com a maior dificuldade no tratamento das estirpes resistentes. O uso disseminado de antibióticos de largo espectro e o desinvestimento na investigação de novos antibacterianos nas últimas três décadas levaram a que existam menos opções para tratar as infeções por BMR. ${ }^{6}$ Por fim, nos últimos anos verificou-se um aumento dos casos de infeção por BMR descritos na comunidade, evidenciando o dado preocupante que estas bactérias já 'circulam' fora do meio hospitalar. ${ }^{1,2}$

\section{Definições}

Em 2012 o European Center for Disease Prevention and Control (ECDC) e o Centers for Disease Control and Prevention $(C D C)$ publicaram um consenso para a definição da multirresistência bacteriana. ${ }^{7}$ Este consenso trouxe maior uniformidade na definição destes agentes, permitindo comparar os dados com maior fidedignidade. Consideram-se as seguintes definições para a resistência bacteriana:

- Multirresistente: não suscetível a pelo menos um agente em 3 categorias de antimicrobianos;

- Extensivamente resistente: não suscetível a pelo menos um agente de todas, exceto $\leq 2$ categorias de antimicrobianos;

- Pan-resistente: não suscetível a todos os agentes de todas as categorias de antimicrobianos.

Para além das definições genéricas acima referidas, importa salientar dois aspetos de relevância clínica e epidemiológica. O primeiro diz respeito às bactérias multirresistentes consideradas mais letais e de maior disseminação. Rice et $a^{\beta}{ }^{\beta}$ usaram o acrónimo ESKAPE para as referir: Enterococcus spp, Staphylococcus aureus, Klebsiella pneumoniae, Acinetobacter baumannii, Pseudomonas aeruginosa e Enterobacter spp. Principalmente nas unidades de cuidados intensivos pediátricos e neonatais, estas são as bactérias mais relevantes a vigiar do ponto de vista epidemiológico. ${ }^{7,8} \mathrm{O}$ segundo aspeto diz respeito à resistência específica destas bactérias a certos antibacterianos, tornando mais difícil a missão de as erradicar. Assim, considera-se resistência: à meticilina para Staphylococcus aureus (MRSA); à vancomicina para Enterococcus spp (VRE); aos carbapenemos para Acinetobacter baumannii; às cefalosporinas de terceira geração para as Enterobacteriaceae - Citrobacter, Enterobacter, Escherichia, Klebsiella, Morganella, Proteus, Serratia, Yersinia (indicador da possibilidade de produção de beta-lactamases de espectro estendido ESBL). Por este motivo, foram definidas classes antimicrobianas específicas a serem testadas para cada bactéria e que contribuem para a sua definição (listadas em tabelas específicas para cada um dos agentes mencionados). ${ }^{7}$

\section{Pertinência e objetivos}

Realizámos um estudo descritivo dos episódios infeciosos por BMR na Unidade de Cuidados Intensivos Neonatais (UCIN) em dez anos com o objetivo geral de determinar as taxas de incidência destas infeções. Como objetivos específicos definimos os seguintes: identificar as BMR mais frequentes; conhecer a epidemiologia das BMR ao longo de uma década; descrever as infeções por BMR (local de isolamento; clínica; mortalidade); conhecer os fatores de risco associados à infeção por BMR; comparar com os dados nacionais e internacionais publicados. Em Portugal, de acordo com a pesquisa realizada nas publicações de referência, este é um dos estudos de incidência com maior duração realizado na Pediatria e em particular numa unidade de Cuidados Intensivos Neonatais.

\section{MATERIAL E MÉTODOS}

Trata-se de um estudo de incidência, retrospetivo, descritivo dos episódios infeciosos por BMR numa UCIN de apoio perinatal diferenciado nível III, ocorridos no período de 01/01/2008 a 31/12/2017. O estudo foi aprovado pela Comissão de Ética do Hospital Garcia de Orta.

\section{Amostra}

A amostra foi obtida através da base de dados informática do laboratório de Microbiologia Hospitalar, tendo sido recolhidos todos os isolamentos microbiológicos em qualquer produto biológico pertencentes aos recém-nascidos (RN) internados na UCIN.

Foram definidos os seguintes critérios de inclusão:

- Definição de BMR mediante os critérios publicados no consenso do ECDC / CDC7;

- Isolamento de BMR após 48 horas de internamento (infeção associada aos cuidados de saúde - IACS);

- Infeção comprovada ou suspeita:

- Isolamento de microrganismo em fluídos estéreis (sangue, urina, líquido cefalorraquidiano, líquido pleural);

- Isolamento de microrganismo em fluido ou tecido não estéril (secreções, pele, mucosas, feridas abertas) e agravamento clínico ou laboratorial (elevação da proteína $\mathrm{C}$ reativa). Foi considerado agravamento clínico a evidência de deterioração respiratória (necessidade de oxigénio suplementar, ventilação ou agravamento dos parâmetros de ventilação), a deterioração hemodinâmica (má perfusão, hipotensão, aumento da frequência cardíaca, necessidade de expansão da volemia ou suporte inotrópico) e a alteração do estado geral (hipotonia ou menor reatividade).

Os critérios de exclusão foram os seguintes:

- Colonização: considerada por isolamento de microrganismo em fluido ou tecido não estéril (secreções, pele, mucosas, feridas abertas) sem causar agravamento clínico ou laboratorial;

- Isolamento da mesma estirpe de BMR, no mesmo 
RN, no mesmo internamento: foi contabilizado apenas o primeiro episódio infecioso (exclusão dos episódios seguintes pela possibilidade de colonização pela BMR e infeção por outro agente não identificado);

- Isolamento de BMR em mais do que um produto biológico na mesma infeção: foi contabilizado apenas como um episódio infecioso (exclusão por tratar-se da mesma infeção, mas com maior disseminação).

Foram aferidos os seguintes indicadores de vigilância epidemiológica:

- Incidência de episódios infeciosos por BMR por 100 internamentos;

- Incidência de episódios infeciosos por BMR por 1000 dias de internamento;

- Taxa de letalidade associada às infeções por BMR;

- Taxa de letalidade associada às infeções associadas aos cuidados de saúde;

- Taxa de mortalidade global da UCIN.

Foram ainda analisados os fatores de risco clássicos para as infeções associadas aos cuidados de saúde, considerados também noutros estudos portugueses que abordam as infeções associadas aos cuidados de saúde. ${ }^{9,10}$ No caso dos dispositivos invasivos (cateter venoso central, ventilação invasiva, nutrição parentérica, sonda vesical), foi considerado como fator de risco a sua utilização até 48 horas antes do início dos sinais, sintomas ou do isolamento da bactéria. No caso da antibioticoterapia e da cirurgia foi considerado o intervalo temporal de cinco dias prévios.

\section{Análise estatística}

O tratamento dos dados foi realizado através dos programas Excel Windows $7^{\circledR}$ e SPSS (Statistical Package for Social Sciences) ${ }^{\circledR}$ versão 22. A análise da distribuição dos dados foi realizada com recurso ao teste de Shapiro-Wilk e a inferência estatística foi efetuada com o teste de correlação de Spearman para as variáveis não paramétricas contínuas. Tentou-se verificar uma correlação entre os anos incluídos no estudo e a taxa de incidência anual de infeções hospitalares por BMR, a taxa de incidência de infeções hospitalares por BMR/100 internamentos e a taxa de incidência de infeções hospitalares por BMR/1000 dias. Foi considerado um nível de significância de $p<0,05$.

\section{RESULTADOS}

No período de estudo ocorreram 90 isolamentos de BMR. Foram incluídos na análise 64 episódios infeciosos correspondentes a 62 RN. Excluíram-se quatro episódios infecciosos precoces (< 48 horas), 18 isolamentos da mesma estirpe de BMR no mesmo RN e quatro isolamentos da mesma BMR no mesmo episódio em dois produtos biológicos. Não se verificaram exclusões do estudo por ausência de agravamento clínico ou laboratorial. Dos 64 episódios incluídos, todos tiveram agravamento clínico e 41 (64\%) tiveram agravamento laboratorial.

A caracterização da amostra está descrita na Tabela 1. Os dados são coincidentes com as características gerais da UCIN tendo em conta o seu carácter de apoio perinatal diferenciado. De salientar que $42 \%$ dos RN com episódios infeciosos por BMR tinham idade gestacional ao nascimento $<28$ semanas, $61 \%$ tinham peso ao nascimento inferior a $1000 \mathrm{~g} \mathrm{e} 64 \%$ tinham peso à data de isolamento da BMR inferior a $1500 \mathrm{~g}$.

Neste período de 10 anos foi evidente o predomínio da família Enterobacteriaceae, em particular de Klebsiella pneumoniae, como está demonstrado na Tabela 2. Seguiram-se Staphylococcus aureus meticilino-resistente, Acinetobacter baumannii e a Pseudomonas aeruginosa. Não se isolou nenhuma estirpe de Enterococcus spp multirresistente.

No sentido de perceber que tipo de infeções provocou as BMR, analisámos também os isolamentos no mesmo episódio, mas em produtos diferentes $(n=4)$ que foram excluídos da contabilização geral dos episódios. Assim, quanto ao tipo de infeção ocorrida $(n=68)$ tivemos a seguinte distribuição: pneumonias associadas à ventilação - $47,1 \%$ (com sépsis associada em 4,6\%); sépsis isolada - 29,4\%; conjuntivite - 14,7\%; celulite/ferida operatória - 4,4\%;

Tabela 1 - Descrição da amostra de episódios infeciosos e do movimento da UCIN (2008 - 2017)

\begin{tabular}{|c|c|c|}
\hline Variáveis & Amostra $(n=64)$ & UCIN $(n=1962)$ \\
\hline Sexo & $\begin{array}{l}\text { Masculino: } n=34(53,1 \%) \\
\text { Feminino: } n=30(46,9 \%)\end{array}$ & $\begin{array}{l}\text { Masculino: } n=1102(56,2 \%) \\
\text { Feminino: } n=860(43,8 \%)\end{array}$ \\
\hline Idade gestacional ao nascimento & $\begin{array}{l}\text { Mediana: } 28 \text { S e } 6 \text { d } \\
\text { (mín: } 24 \text { S; máx: } 39 \text { S e } 5 \text { d; iiq: } 5,72 \text { S) }\end{array}$ & $\begin{array}{l}\text { Mediana: } 33 \text { S } \\
\text { (mín: } 23 \text { S; máx: } 41 \text { S) }\end{array}$ \\
\hline Peso ao nascimento & $\begin{array}{l}\text { Mediana: } 885 \text { g } \\
\text { (mín: } 510 \text { g; máx: } 4180 \text { g; iiq: } 755 \text { g) }\end{array}$ & $\begin{array}{l}\text { Mediana: } 1805 \mathrm{~g} \\
\text { (mín: } 490 \text { g; máx: } 4600 \mathrm{~g} \text { ) }\end{array}$ \\
\hline Dias de internamento & $\begin{array}{l}\text { Mediana: } 65,8 \text { d } \\
\text { (mín: } 6 \text { d; máx: } 252 \text { d; iiq: } 60 \text { d) }\end{array}$ & $\begin{array}{l}\text { Mediana: 18,4d } \\
\text { (mín: } 1 \text { d; máx: } 335 \text { d) }\end{array}$ \\
\hline Dia de internamento ao isolamento & $\begin{array}{l}\text { Mediana: } 18,5 \mathrm{~d} \\
\text { (mín: } 3 \mathrm{~d} \text {; máx: } 70 \text { d; iiq: } 23 \text { d) }\end{array}$ & NA \\
\hline Idade corrigida ao isolamento & $\begin{array}{l}\text { Mediana: } 31 \text { S } \\
\text { (mín: } 29 \text { S; máx: } 40 \text { S; iiq: 4,14 S) }\end{array}$ & NA \\
\hline Peso ao isolamento & $\begin{array}{l}\text { Mediana: } 1231,5 \mathrm{~g} \\
\text { (mín: } 520 \mathrm{~g} \text {; máx: } 4200 \mathrm{~g} \text {; iiq: } 829 \mathrm{~g} \text { ) }\end{array}$ & NA \\
\hline
\end{tabular}

S: semanas; d: dias; g: gramas; mín: mínimo; máx: máximo; iiq: intervalo inter-quartil; UCIN: unidade de cuidados intensivos neonatais; NA: não aplicável 
Tabela 2 - Distribuição das bactérias multirresistentes isoladas

\begin{tabular}{lcc}
\hline Bactéria multirresistente & Frequência $(\%)$ & Valor absoluto $(\mathrm{n})$ \\
\hline Enterobacteriaceae & $71,9 \%$ & 46 \\
Klebsiella pneumoniae & $25,0 \%$ & 16 \\
Enterobacter spp & $21,9 \%$ & 14 \\
Escherichia coli & $14,1 \%$ & 9 \\
Serratia spp & $7,8 \%$ & 5 \\
Proteus spp & $1,6 \%$ & 1 \\
Citrobacter spp & $1,6 \%$ & 1 \\
Staphylococcus aureus meticilino-resistente & $18,8 \%$ & 12 \\
Acinetobacter baumannii & $6,3 \%$ & 4 \\
Pseudomonas aeruginosa & $3,1 \%$ & 2 \\
\hline
\end{tabular}

pielonefrite $-1,5 \%$; meningite $-1,5 \%$; peritonite $-1,5 \%$. A distribuição detalhada dos isolamentos por produto biológico encontra-se na Tabela 3. Como referido, a Klebsiella pneumoniae foi um dos agentes mais relevantes, tendo sido a única espécie produtora de beta-lactamases de espectro estendido encontrada na nossa amostra. Salienta-se também a preponderância do MRSA como agente de conjuntivite (sete em 10 isolamentos de BMR no exsudado ocular), dado que pode ser tido como indicador de uma das formas de reservatório natural deste agente (risco para o próprio e para os RN próximos localmente). De referir também que $75 \%(n=3)$ das estirpes de Acinetobacter baumannii isoladas eram resistentes aos carbapenemos, dado relevante do ponto de vista epidemiológico e que valida a restrição necessária ao uso destes antibióticos de largo espectro.

A análise dos fatores de risco é difícil dada a variabilidade entre os casos e a dificuldade em definir qual o período prévio ao episódio infecioso que se deverá considerar para a causa-efeito. ${ }^{9,10}$ Constatámos que a maioria dos doentes tinha pelo menos um fator de risco clássico para infeção nos cuidados intensivos - 90,6\% ( $n=58)$. Dos fatores de risco analisados, referimos: cateter venoso central (89,1\%); ventilação invasiva $(68,8 \%)$; nutrição parentérica $(79,7 \%)$; sonda vesical (3,1\%); cirurgia (12,5\%); antibioticoterapia prévia ao isolamento de BMR $(78,1 \%)$. Este último é um fator relevante a ser tido em conta na perspetiva de controlo destas infeções dado que alguns agentes antibacterianos são indutores de resistência. Os antibióticos mais utilizados na nossa amostra integram o protocolo local de sépsis neonatal precoce (ampicilina e gentamicina) e tardia (vancomicina e cefotaxime).

Ocorreram sete óbitos na amostra obtida, o que corresponde a uma taxa de letalidade associada às BMR de $10,9 \%$. A bactéria mais 'letal' foi a Klebsiella pneumoniae produtora de ESBL $(n=3$; letalidade $=4,68 \%)$, provocando quadros clínicos de sépsis fulminante. As outras BMR envolvidas foram: Serratia marcescens $(n=1$; letalidade $=$ $1,56 \%)$, Enterobacter cloacae $(n=1$; letalidade $=1,56 \%)$, Enterobacter aerogenes $(n=1$; letalidade $=1,56 \%)$ e MRSA

Tabela 3 - Distribuição das bactérias multirresistentes isoladas por produto biológico

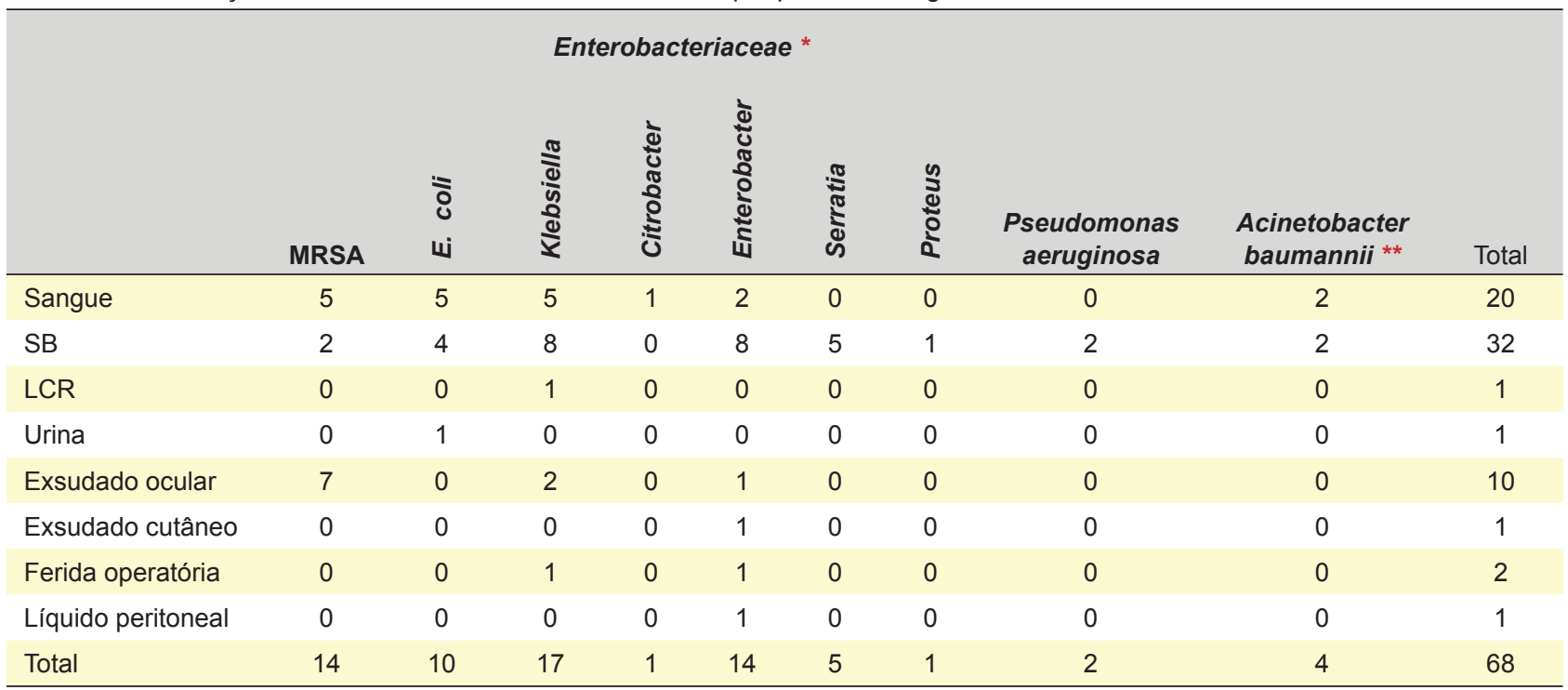

MRSA: Staphylococcus aureus meticilino-resistente; SB: secreções brônquicas; LCR: líquido cefalo-raquidiano

* Foram isoladas sete estirpes produtoras de beta-lactamases de espectro estendido, sendo todas Klebsiella pneumoniae

** Foram isoladas três estirpes resistentes aos carbapenemos 
( $n=1$; letalidade $=1,56 \%$ ). É difícil relacionar a mortalidade nestes casos à infeção por BMR dada a miríade de fatores que podem ser responsáveis pelo óbito nos RN prematuros. No mesmo período, a taxa de mortalidade global na UCIN foi de $4,4 \%$ e a taxa de letalidade por infeções associadas aos cuidados de saúde foi de $7 \%$.

A evolução dos episódios infeciosos por BMR ao longo da última década na UCIN está representada na Fig. 1. Verificou-se uma média de 6,4 episódios por ano. Traçando uma linha de acordo com o valor médio (Fig. 1 - linha tracejada cinzento) percebe-se que as infeções por BMR ocorreram em três surtos (Fig. 1 - retângulos tracejados vermelhos): em 2009, provocado por Serratia marcescens; de 2012 a 2013, provocado por Klebsiella pneumoniae e Enterobacter spp; de 2015 a 2017, provocado por KlebsieIla pneumoniae, MRSA e Escherichia coli. Esta análise é relevante pois cada um destes agentes tem medidas de controlo específicas relacionadas com os seus fatores de risco.

As taxas de incidência calculadas (Tabela 4) refletem a evolução por surtos acima referida. No período de 2008 a 2017, a taxa de incidência de episódios infeciosos por BMR na UCIN HGO foi de 3,26 episódios por 100 internamentos, correspondentes a 1,78 episódios por 1000 dias de internamento.

Realizou-se a análise comparativa das taxas de infeção ao longo dos 10 anos. Verificou-se uma correlação positiva dos episódios infeciosos com a evolução ao longo dos anos, mas sem significado estatístico $(p=0,074)$. Também não houve significado estatístico para a evolução das taxas de incidência por 100 internamentos $(p=0,248)$ e por 1000 dias de internamento $(p=0,137)$. Assim, apesar de uma tendência para o aumento do número de infeções por BMR, esta diferença não se verificou estatisticamente significativa.

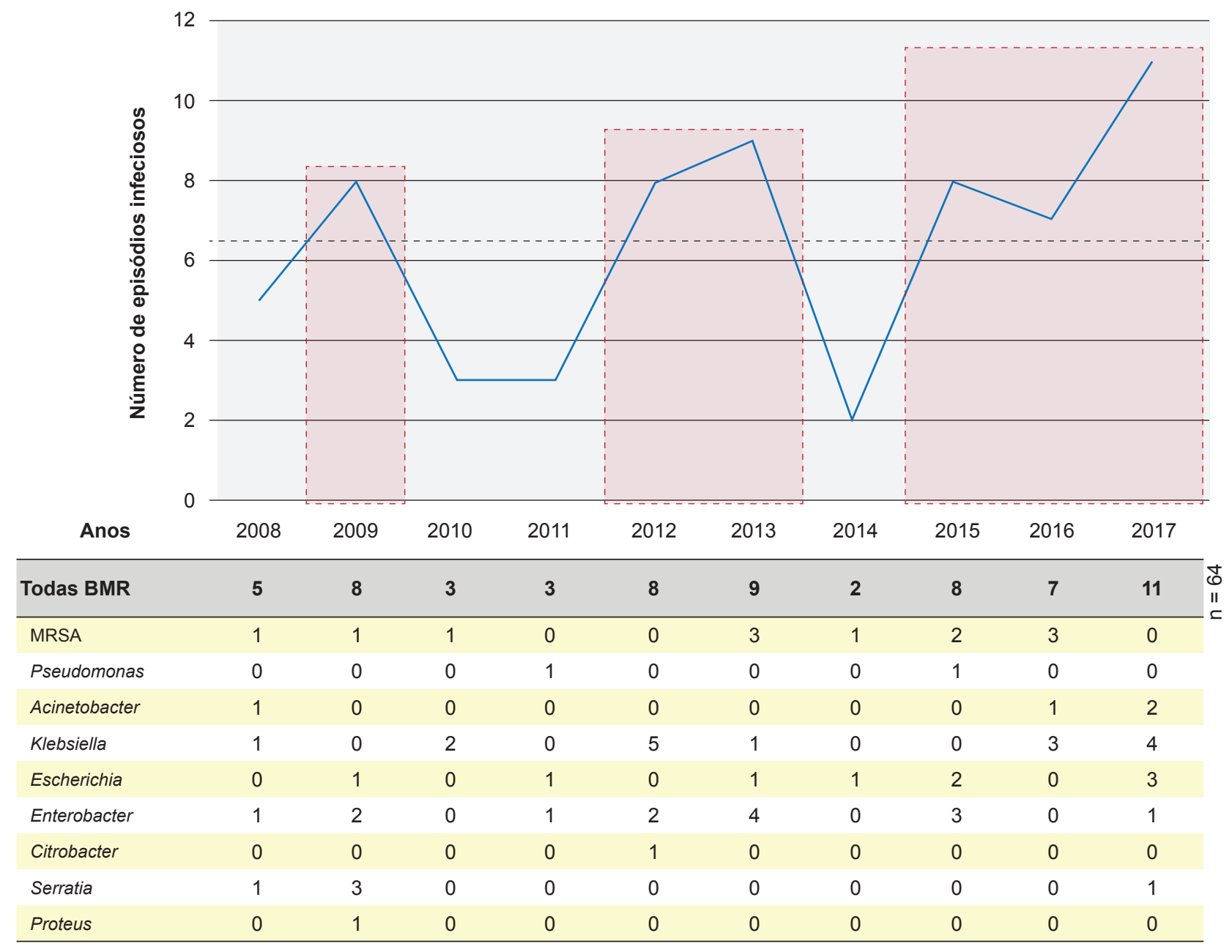

Figura 1 - Distribuição dos episódios infeciosos por bactérias multirresistentes por ano. Evolução dos episódios infeciosos por bactérias multirresistentes de 2008 a 2017. A linha azul escura corresponde à evolução do total de episódios infeciosos por bactérias multirresistentes. A linha tracejada cinzenta correspondente à média de episódios infeciosos por bactérias multirresistentes nos 10 anos de estudo (6,4 episódios infeciosos/ano). Os retângulos tracejados vermelhos correspondem aos períodos de elevação do número de episódios acima da média de episódios infeciosos por bactérias multirresistentes. Verificaram-se três períodos acima da média (surtos): 2009; 2012 - 2013; 2015 - 2017.

BMR: bactéria multirresistente; MRSA: Staphylococcus aureus meticilino-resistente 
Tabela 4 - Incidência das infeções por bactérias multirresistentes na UCIN de 2008 a 2017

\begin{tabular}{cccccc}
\hline Ano & $\begin{array}{c}\text { Internamentos } \\
(\mathrm{n})\end{array}$ & $\begin{array}{c}\text { Internamentos } \\
(\text { dias })\end{array}$ & $\begin{array}{c}\text { EI BMR } \\
(\mathrm{n})\end{array}$ & $\begin{array}{c}\text { TI BMR } \\
\text { (por 100 internamentos) }\end{array}$ & $\begin{array}{c}\text { TI BMR } \\
\text { (por 1000 dias de internamento) }\end{array}$ \\
\hline 2008 & 216 & 3957 & 5 & 2,31 & 1,26 \\
2009 & 189 & 3809 & 8 & 4,23 & 2,10 \\
2010 & 213 & 3849 & 3 & 1,41 & 0,77 \\
2011 & 175 & 3369 & 3 & 1,71 & 0,89 \\
2012 & 210 & 3535 & 8 & 3,81 & 2,26 \\
2013 & 168 & 3528 & 9 & 5,36 & 2,55 \\
2014 & 176 & 3265 & 2 & 1,14 & 0,61 \\
2015 & 214 & 3523 & 8 & 3,74 & 2,27 \\
2016 & 184 & 3386 & 7 & 3,80 & 2,06 \\
2017 & 217 & 3550 & 11 & 5,07 & 3,09 \\
$2008-2017$ & 1962 & 35771 & 64 & 3,26 & 1,78 \\
\hline
\end{tabular}

UCIN: unidade de cuidados intensivos neonatais; El: episódios infeciosos; BMR: bactérias multirresistentes; TI BMR: taxa de incidência de infeções por bactéria multirresistente

\section{DISCUSSÃo}

A incidência de infeções por agentes multirresistentes é mais elevada nas unidades de cuidados intensivos de outros grupos etários comparativamente com a população pediátrica e em particular a neonatal. ${ }^{11,12}$ Os dados publicados referentes à população pediátrica, principalmente a nível nacional, são reduzidos. No entanto, existe a noção clínica que a multirresistência tem sido um problema crescente nos RN internados nas UCIN. Dada a imaturidade imunológica, maior sobrevida nas últimas décadas, internamentos mais prolongados, atraso na instituição de terapêutica adequada (pela clínica inespecífica) e menos opções terapêuticas (pela toxicidade farmacológica), os RN prematuros são um grupo particularmente vulnerável à infeção em geral e em particular por BMR. A maior sobrevida dos grandes prematuros graças à evolução da neonatologia trouxe uma nova população, com várias particularidades. Uma delas é a colonização por agentes multirresistentes que serão disseminados para fora do ambiente hospitalar, para a comunidade. A questão da colonização dos RN nas UCIN tem sido alvo de debate quanto às suas implicações. A colonização por BMR pode evoluir para a infeção nos RN em estados de maior vulnerabilidade, podendo estes servir também de reservatório natural para as BMR com possibilidade de infeção de outros RN. ${ }^{6}$ Esta é uma problemática que interfere mesmo com a gestão e organização das UCIN, dada a necessidade de encerramento de unidades para períodos de descolonização.

\section{A multirresistência deve ser enquadrada numa realida- de internacional, nacional e local.}

Os dados reunidos pela Rede Europeia de Vigilância da Resistência Antimicrobiana (EARS-Net) colocam em evidência o aumento das infeções por BMR e o seu impacto na morbilidade e mortalidade. ${ }^{2,13}$ De acordo com o último relatório publicado (2017), o MRSA continua a constituir-se como a principal BMR. ${ }^{13}$ No entanto, verifica-se desde 2007 uma tendência progressiva para o aumento das infeções por Enterobacteriaceae (número total seis vezes superior) e por Acinetobacter. Existem poucos estudos de incidência global e escassos estudos multicêntricos publicados. Salienta-se o estudo realizado em cinco unidades de cuidados intensivos pediátricos da área metropolitana de Paris, que reportou uma incidência de 1,4 episódios por 100 internamentos. ${ }^{14} \mathrm{O}$ MRSA foi o principal agente isolado seguindo-se a Klebsiella penumoniae. De salientar que estes dados foram obtidos após a instituição de medidas de prevenção para estas infeções. Outros estudos europeus publicados, também reportam taxas de incidência específicas por agente mais baixas, mas não foram realizados exclusivamente em UCIN. ${ }^{15,16}$ Este dado é relevante na medida em que a risco infecioso, em particular por BMR, nas UCIN é tendencialmente superior à dos restantes internamentos pediátricos. ${ }^{11}$ Nos países desenvolvidos encontram-se várias publicações de surtos nas diferentes UCIN, verificando-se uma transição dos principais agentes responsáveis. Depois de um predomínio de MRSA relatado no final dos anos 90 , na última década verifica-se que Enterobacteriaceae têm sido responsáveis pela maioria dos surtos..$^{17,18}$ Este dado coloca em evidência a ideia de que as medidas de controlo de infeção dirigidas a MRSA talvez tenham sido eficazes, mas que poderão não ser aplicáveis à prevenção de infeções por outros agentes. De referir também que o ligeiro predomínio das infeções no sexo masculino é consistente com os dados internacionais e nacionais. ${ }^{14,19,20}$

A nível nacional, estão publicados dois estudos relativos à incidência de infeções por BMR em idade pediátrica. O primeiro estudo, realizado num período de cinco anos, incluiu internamentos cirúrgicos além das enfermarias médicas e de cuidados intensivos. No referido período são relatados 106 isolamentos, 45 infeções e seis óbitos na amostra estudada. O principal agente foi MRSA e a taxa de incidência foi de 0,27 episódios por 100 internamentos correspondentes a 0,4 episódios por 1000 dias de internamento. ${ }^{19} \mathrm{O}$ segundo estudo, realizado num período de sete anos, incluiu internamentos em todo o Serviço de Pediatria (Neonatologia e enfermaria de Pediatria). Foram relatados 42 isolamentos, 34 infeções e zero óbitos. As principais BMR foram Enterobacteriaceae e a taxa de incidência foi de 0,32 episódios por 100 internamentos $(0,22$ 
na Pediatria; 0,89 na Neonatologia). ${ }^{20}$ Nenhum dos estudos descreve as características da amostra neonatal (idade gestacional, peso, dias de internamento), dados que são relevantes para retirar ilações das comparações entre os estudos e a realidade dos respetivos hospitais. A inclusão de internamentos noutros setores pediátricos (menor risco para a multirresistência) contribui para as menores taxas de incidência relatadas, dificultando a comparação com o presente estudo.

Localmente, este estudo oferece-nos um ponto de partida para a melhoria dos cuidados, vigilância adequada e mudança necessária visando a redução destas infeções. Da análise dos resultados, para além da incidência global sobressaem alguns aspetos. O primeiro diz respeito à população mais afetada. Efetivamente os RN com menor peso e menor idade gestacional são os mais suscetíveis à infeção e aqueles em que poderá haver uma tendência para a instituição mais precoce de antibioticoterapia. ${ }^{9,10}$ No entanto, é necessária maior contenção nesta prescrição com critérios mais estritos dada a possibilidade da emergência de estirpes multirresistentes. Serão estes os RN que também necessitarão de maiores precauções e medidas genéricas contra a infeção hospitalar e a sua disseminação.

Outro aspeto diz respeito às principais BMR isoladas - Enterobacteriaceae. É essencial entender que fatores específicos mais contribuem para a emergência destas bactérias. Tal como demonstrado no presente estudo, em $78 \%$ dos episódios infeciosos os RN foram expostos a antibioticoterapia prévia ao isolamento de uma BMR e o cefotaxime foi o terceiro antibiótico mais prescrito neste contexto. As cefalosporinas de terceira geração são indutoras de resistência bacteriana durante a terapêutica através da seleção de estirpes com o gene da beta-lactamase nos cromossomas e da estimulação da emergência de bactérias ESBL codificadas em plasmídeos (Enterobacteriaceae). ${ }^{6}$ É necessário perceber a suscetibilidade antibacteriana local das bactérias envolvidas na sépsis neonatal tardia para encontrar alternativas aceitáveis e mais seguras.

A evolução por surtos, evidente no nosso estudo, vai ao encontro da necessidade de entender melhor os diferentes agentes, os seus fatores de risco e meios de disseminação. Para além de Enterobacteriaceae, os isolamentos de MRSA são outro exemplo deste conceito. Metade dos isolamentos deste agente na nossa UCIN (7/14) foram encontrados no exsudado ocular, sendo mesmo o agente de $70 \%$ das conjuntivites por BMR. Esta infeção, pouco relevante clinicamente, tratada em muitas ocasiões de forma empírica, pode na verdade tornar-se uma fonte de multirresistência. Os RN infetados poderão constituir reservatórios naturais e assim propagar o agente. Do ponto de vista de vigilância e prevenção da infeção é necessário ponderar na realização da colheita do exsudado ocular antes do tratamento empírico, principalmente se existirem casos de infeções mais graves por MRSA no mesmo período na UCIN.

No outro extremo, verificámos que em 2014 o número de infeções ficou abaixo da média registada. Efetivamente, a única justificação encontrada relaciona-se com uma campanha hospitalar decorrida no final de 2013 que abrangeu um conjunto de formações dirigidas aos profissionais de saúde para a lavagem das mãos no contacto com os doentes. As formações com componente teórico e prático, foram seguidas de auditorias regulares durante o ano. Este dado ressalva a importância de uma medida simples na prevenção destas infeções. No entanto, a campanha já foi repetida, sem o mesmo efeito prático nos anos seguintes.

Dada a vulnerabilidade do RN prematuro, com várias causas de mortalidade e morbilidade, é difícil atribuir a infeção por BMR como responsável pelo óbito nesta população. No entanto, ao comparar a taxa de letalidade por BMR $(10,9 \%)$ calculada no presente estudo com a taxa de mortalidade global $(4,4 \%)$ e com a taxa de letalidade por infeções associadas aos cuidados de saúde (7\%) na UCIN HGO no mesmo período, consegue-se inferir indiretamente o impacto da infeção por agentes multirresistentes na mortalidade. Seria relevante realizar um estudo de impacto da mortalidade e morbilidade neonatal da infeção por BMR.

No sentido de reduzir localmente as infeções multirresistentes, é essencial considerar as seguintes medidas: conhecer a epidemiologia local, a incidência das bactérias multirresistentes para adotar as medidas mais específicas; educar os profissionais de saúde, todo o staff da UCIN assim como os pais e visitantes para as medidas de controlo destas infeções; adotar uma política de antibioticoterapia rigorosa, evitando agentes indutores de resistência (cefalosporinas de terceira geração), reservando antibacterianos poderosos apenas para as infeções multirresistentes (carbapenemos), tratando apenas a infeção e não a colonização, reduzindo a duração da terapêutica ao mínimo necessário; vigiar a ocorrência destas infeções por BMR e dos seus surtos; adotar medidas de controlo/isolamento das crianças infetadas e dos seus acompanhantes; lavar as mãos; considerar a erradicação dos reservatórios naturais das bactérias multirresistentes através de agentes tópicos (mupirocina ou clorexidina nas colonizações por MRSA).

Por fim, importa reforçar que outros aspetos locais devem ser tidos em conta quando se analisa a multirresistência. Nos últimos anos têm surgido publicações reportando fatores como o burnout dos profissionais de saúde e o understaffing nas unidades de cuidados intensivos associados à ocorrência de surtos de infeções multirresistentes. ${ }^{18,21} \mathrm{~A}$ mudança de paradigma passa por entender que para além de instituir medidas generalistas (igualmente importantes) são necessárias medidas específicas adaptadas aos diferentes locais e agentes.

O presente estudo tem como limitações o facto de ser retrospetivo, de ter sido realizado num período limitado de tempo, numa amostra reduzida pertencente a um único centro, podendo não refletir a realidade nacional.

\section{CONCLUSÃO}

O primeiro estudo de incidência das infeções por BMR na nossa UCIN permitiu conhecer a incidência local, percebendo-se quais as BMR envolvidas para que se consiga conhecer a epidemiologia local (primeiro passo para a 
redução destas infeções), abordar os fatores de risco específicos, dando início à vigilância adequada e à mudança necessária. Ressalvou também o predomínio de Enterobacteriaceae e da evolução por surtos. Evidenciou também a relevância das infeções por BMR, responsáveis por uma taxa de letalidade superior à das infeções genéricas associadas aos cuidados de saúde.

Partindo destes dados poderão ainda ser realizados estudos procedentes de aferição do impacto das infeções por estes agentes multirresistentes ou do impacto das medidas adotadas para impedir estas infeções. Estes dados de vigilância epidemiológica são fulcrais para a melhoria de cuidados e evolução da neonatologia.

\section{OBSERVAÇÕES}

Trabalho apresentado como comunicação oral nas XLVII Jornadas Nacionais de Neonatologia que decorreu de 15 a 16 de Novembro de 2018, em Braga.

\section{REFERÊNCIAS}

1. O'Neill J. Tackling drug resistant infections globally: final report and recommendations. The review on antimicrobial resistance. London: Welcome Trust \& HM Governement; 2016.

2. Frieden T. Antibiotic resistance threats in the United States. Washington: U.S. Department of Health and Human Services, Centers for Disease Control and Prevention; 2013.

3. Cassini A, Hogberg LD, Plachouras D, Quattrocchi A, Hoxha A, Simonsen GS, et al. Attributable deaths and disability-adjusted lifeyears caused by infections with antibiotic-resistant bacteria in the EU and the European Economic Area in 2015: a population-level modelling analysis. Lancet infect Dis. 2019;19:56-66.

4. Boucher HW, Talbot GH, Bradley JS, Edwards JE, Gilbert D, Rice LB, et al. Bad bugs, no drugs: no ESKAPE! An update from the Infectious Diseases Society of America. Clin Infect Dis. 2009;48:1-12.

5. Chopra I, Schofield C, Everett M, O’Neill A, Miller K, Wilcox M, et al. Treatment of health-care-associated infections caused by gram-negative bacteria: a consensus statement. Lancet Infect Dis. 2008;8:133-9.

6. Boucher HW, Talbot GH, Benjamin DK, Bradley J, Guidos RJ, Jones $\mathrm{RN}$, et al. 10 × 20's - Development of new drugs active against gramnegative bacilli: an update from the Infectious Diseases Society of America. Clin Infect Dis. 2013;56:1685-94.

7. Magiorakos AP, Srinivasan A, Carey RB, Carmeli Y, Falagas ME, Giske $\mathrm{CK}$, et al. Multidrug-resistant, extensively drug-resistant and pan-drugresistant bacteria: an international expert proposal for interim standard definitions for acquired resistance. Clin Microbiol Infect. 2012;18:26881.

8. Rice LB. Federal funding for the study of antimicrobial resistance in nosocomial pathogens: no ESKAPE. J Infect Dis. 2008;197:1079-81.

9. Pereira H, Grilo E, Cardoso P, Noronha N, Resende C. Fatores de risco para sépsis associada aos cuidados de saúde em recém-nascidos de muito baixo peso. Acta Med Port. 2016;29:261-67.

10. Órfão F. Infeção associada aos cuidados de saúde numa unidade de cuidados intensivos neonatais (2010-2014). Tese de mestrado integrado de Medicina. Lisboa: Faculdade de Medicina, Universidade de Lisboa; 2016.

\section{PROTEÇÃO DE PESSOAS E ANIMAIS}

Os autores declaram que os procedimentos seguidos estavam de acordo com os regulamentos estabelecidos pelos responsáveis da Comissão de Investigação Clínica e Ética e de acordo com a Declaração de Helsínquia da Associação Médica Mundial.

\section{CONFIDENCIALIDADE DOS DADOS}

Os autores declaram ter seguido os protocolos do seu centro de trabalho acerca da publicação de dados.

\section{CONFLITO DE INTERESSES}

Os autores declaram não ter qualquer conflito de interesse relativamente ao presente artigo.

\section{FONTES DE FINANCIAMENTO}

Os autores declaram não ter recebido qualquer subsídio ou bolsa relativamente ao presente artigo.

11. Patel SJ, Saiman L. Antibiotic resistance in NICU pathogens: mechanisms, clinical impact and prevention including antibiotic stewardship. Clin Perinatol. 2010;37:547-63.

12. Arias CA, Murray BE. Antibiotic-resistant bugs in the $21^{\text {st }}$ century - a clinical super-challenge. N Engl J Med. 2009;360:439-43.

13. European Centre for Disease Prevention and Control. Surveillance of antimicrobial resistance in Europe - Annual report of the European Antimicrobial Resistance Surveillance Network (EARS-Net) 2017. Stockholm: ECDC; 2018.

14. Raymond J, Nordmann P, Doit C, Vu Thien H, Guibert M, Ferroni A, et al. Multidrug-resistant bacteria in hospitalized children: a 5-year multicenter study. Pediatrics. 2007;119:789-803.

15. Folgori L, Livadiotti S, Carletti M, Bielicki J, Pontrelli G, Ciofi Degli Atti $\mathrm{ML}$, et al. Epidemiology and clinicaloutcomes of multidrug-resistant, gram-negative bloodstream infections in a European terciary pediatric hospital during a 12-month period. Pediatr Infect Dis J. 2014;33:929-32.

16. Geffers C, Gastmeier P. Nosocomial infections and multidrugresistant organisms in Germany: epidemiological data from KISS (the Hospitallnfection Surveillance System). Dtsch Arztebl Int. 2011;108:8793.

17. Johnson J, Quach C. Outbreaks in the neonatal ICU: a review of the literature. Curr Opin Infect Dis. 2017;30:395-403.

18. Stapleton PJ, Murphy M, McCallion N, Brennan M, Cunney R, Drew RJ. Outbreaks of extended spectrum beta-lactamase-producing Enterobacteriaceae in neonatal intensive care units: a systematic review. Arch Dis Child Fetal Neonatal Ed. 2016;101:F72-8.

19. Mação P, Lopes J, Oliveira H, Oliveira G, Rodrigues F. Bactérias multirresistentes associadas aos cuidados de saúde num hospital pediátrico: experiência de cinco anos. Acta Med Port. 2013;26:385-91.

20. Abreu M, Leite J, Portela A, Alves V, Almeida R. Infeções por bactérias multirresistentes em idade pediátrica: estudo retrospetivo de sete anos de um hospital de nível I. Acta Pediatr Port. 2016;47:130-8.

21. Tawfik DS, Sexton JB, Kan P, Sharek PJ, Nisbet CC, Rigdon J, et al. Burnout in the neonatal intensive care unit and its relation to healthcareassociated infections. J Perinatol. 2017;37:315-2. 